\title{
The impact of online teaching videos on Canadian pre-service teachers
}

\author{
Thierry Karsenti \\ University of Montreal, Montreal, Canada, and \\ Simon Collin \\ University of Quebec in Montreal, Montreal, Canada
}

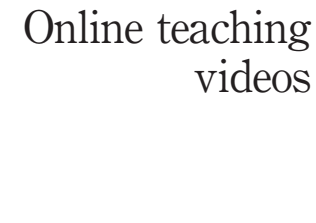

195

Received April 2011 Accepted April 2011

\begin{abstract}
Purpose - One of the major challenges in teacher training programs is the gap between the theory that is presented to pre-service teachers and actual classroom practice. Many researchers, educators, and pre-service teachers have emphasized the difficulty of linking theory and practice in teacher education programs. The purpose of this study is to better understand the impact of online teaching videos on the development of self-efficacy beliefs in pre-service teachers.

Design/methodology/approach - Over 400 student teachers participated in this study. Statistical analyses of questionnaires were conducted to assess the impact of online teaching videos. The results reveal that online videos did affect the self-efficacy beliefs of pre-service teachers.

Findings - Online videos of teaching practices appear to contribute positively to feelings of self-efficacy in pre-service teachers.

Practical implications - Given the importance of self-efficacy for teachers' professional development, online videos could prove highly useful to this end. Apart from the impact of the videos themselves, self-directed learning has the benefit of flexibility in terms of time and space, which is typical of open and distance learning in general. Furthermore, online videos can be readily adapted to individual professional development plans, according to the teacher's needs, in contrast to more formal training programs (either initial or continuing) with their relatively rigid, predetermined contents.
\end{abstract}

Originality/value - This study presents an original self-training online video device that could easily be integrated in teacher training to support effectively their professional development.

Keywords Beliefs, Teachers, Students, Professional education, Online learning, Self development, Video, Canada

Paper type Research paper

\section{Introduction: ICT, videos, and education: a century of promises}

One day, people will learn through electronic circuits (Marshall McLuhan, 1965).

Marshall McLuhan, a Canadian philosopher, showed great foresight when, in the 1960s, he claimed that technologies would one day play a crucial role in education (Garlock and Soles, 1965). But more than 50 years before McLuhan, another visionary, Thomas Edison, had already predicted a great future for technologies in schools. In fact, a few years after making an educational film in 1911, Edison proclaimed that, "Books will soon be obsolete in schools [...] It is possible to teach every branch of human knowledge with the motion picture" (Edison, cited in Reiser, 1987, p. 11). Since

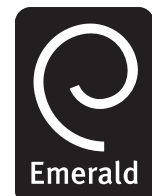

Campus-Wide Information Systems Vol. 28 No. 3, 2011 pp. 195-204

(C) Emerald Group Publishing Limited 1065-0741 DOI $10.1108 / 10650741111145724$ 
CWIS

28,3

\section{6}

Edison's prediction that teaching would be revolutionized by films (or videos), the integration of technologies in education has gone through many transformations and developments, including the use of television, videos, computers, and information and communication technologies (ICT).

Thus, for about a century, technologies have been promised a major role in education. However, since the early 1980s when, for the only time in its history, Time Magazine departed from its annual practice of naming a "Person of the Year" and named a "Machine of the Year", the computer and the internet have become increasingly widespread in schools. In his introduction, Time Magazine publisher John A. Meyers wrote, "Several human candidates might have represented 1982, but none symbolized the past year more richly, or will be viewed by history as more significant, than a machine: the computer" (Meyers, 1983, p. 3). However, the technologies have yet to be used to their fullest potential. For example, the digital video has simplified the process of creating, viewing, and sharing as never before. This opens the way to almost limitless educational potential (Collins and Halverson, 2009).

\section{Problem}

Teacher education programs in Canada face two major challenges: the dichotomy between theory and practice in teacher education programs and the shortage of French-speaking teachers. Online teaching videos could help to meet the challenges in both of these areas.

\subsection{The dichotomy between theory and practice in teacher education programs}

One of the major challenges in teacher education programs is the often-perceived dichotomy between theory and practice (Desjardins, 2000; Van Eijck, 2010) - that is, the gap between the theory that is presented to pre-service teachers at university and the classroom they face during their practica. This difficulty stems largely from the way that theory is presented, usually in an abstract, decontextualized manner that is out of touch with reality and hence irrelevant to everyday teaching practice. This clear-cut, simplified, denaturalized, and often prescriptive approach, appears to be no match for the "messy, indeterminate situations" of the real classroom (Schön, 1987, p. 4) that teachers deal with every day, and that require a combination of knowledge, open-mindedness, insight, and creativity.

During their practicums is usually when pre-service teachers perceive this discrepancy between what they were taught at university and what the associate teacher working in the high school or elementary school classroom does or claims to do, typically seeming to rely largely on hard-earned experience. Consequently, student teachers might feel they were misinformed at university and could have problems connecting theory and practice.

According to Richardson (2001), pre-service teacher training programs continue to prepare teachers in ways that reinforce a transmission model of "teaching as telling". The perception of teaching as knowledge transmission is grounded in an epistemology of technical rationality that views teachers and teacher educators as technicians delivering a prescribed curriculum. In this sense, novice teachers are expected to apply what they have learned. This kind of teaching gives little credence to learning through experience or from experienced teachers (Schön, 1983, 1995). Furthermore, because 
some distance training programs are based on the transmission model, they perpetuate the gap between theory and practice.

\subsection{Overcoming the shortage of French-speaking teachers in Canada}

Canada is the world's second largest country by total area, occupying most of Northern North America, from the Atlantic Ocean in the east to the Pacific Ocean in the West and North into the Arctic Circle. Across Canada's ten provinces and three territories, education must be offered in either English or French, the country's two official languages. This poses many challenges, particularly in areas or provinces where one language, usually French, is a minority language. For example, Ontario, Canada's second largest province, has a substantial shortage of qualified French-speaking teachers. Moreover, although many schools employ some teachers who are not fully qualified, given the lack of teachers removing them from the classroom for further training is extremely unlikely. In order to address this considerable challenge, we decided to implement a distance education program for minority-language (French-speaking) teachers.

However, the candidates quickly raised some issues pointing out that the theoretical material they received needed to be complemented by classroom observations, both to make the course more accessible and to ground the course in reality. Basically, they felt that distance education alone would not fully prepare them to be qualified teachers and would not give them a proper, professional teacher education. This request raised another substantial challenge in turn, because the program they were following did not provide the classroom observation hours or internship opportunities included in the regular teacher-training programs held at the university. The candidates wanted the classroom brought to them, and at times outside regular school hours.

The solution was to develop an online teaching resource called Cyberprofs.org, which contains over 75 video clips of authentic, in-class pedagogical activities and interactions, with comments by experts, teachers, and pupils. In creating this resource, care was taken to preserve the spontaneity and naturalness of the people and activities filmed - an essential element in vicarious learning through modeling and imitation (Bandura, 1997; Poppers and Lipshitz, 1993). The videos can be used to train teachers in Canada and abroad. Each year the site (www.cyberprofs.org) receives over 500,000 visits, which clearly underscores the need for this type of online teacher resource.

\section{Theoretical framework}

\subsection{Educational benefits of ICT}

Schools and universities that provide teacher education programs must cope with a constantly changing environment. They are heading into a maelstrom of digital information, computers, and the internet. Many feel that this technological surge brings countless advantages that schools and universities can and must exploit while carrying out their fundamental mission of providing education. Today, ICT can deliver universal access to knowledge. This offers schools power and reach that not even Edison could have imagined. ICT can simultaneously combine text, images, sound, interactivity, and programming. They can also record events and transmit them around the world. Through the integration and judicious use of ICT, the field of

\section{Online teaching videos}

197 
CWIS

28,3

198 education as a whole could expand enormously, while enjoying significantly improved conditions for collaboration, research, and knowledge production.

\subsection{Impact of videos on initial and ongoing teacher training}

After three years of development, we believe that this project has almost achieved Edison's prediction. From a review of the literature on the use of videos in initial and ongoing teacher training, we have identified some of the main issues, as presented in the next paragraphs: linking theory to practice; anticipating and preparing for teaching practice; analyzing real-life teaching and learning situations; analyzing educational events; developing useful competencies in situ; fostering reflection through either self-observation or observation of others; overcoming distance; and using a diversity of learning models. This section addresses three impacts that are relevant to our research objective.

Anticipating and preparing for teaching practice. The primary potential impact of videos on teacher training is that they allow pre-service teachers to anticipate actual classroom situations so they can better prepare for them. Thus, according to Sherin (2004, p. 13) "Video allows one to enter the world of the classroom without having to be in the position of teaching in-the-moment". Similarly, incorporating videotapes into training programs gives teachers an opportunity to appreciate the realities of classroom teaching and learning. To develop this potential, authentic situations should be used, as opposed to clips of "good practices", as models of recommended practices for teachers in initial or ongoing training programs (Oonk et al., 2004, p. 137). The new self-directed training module was therefore based on authentic situations.

Analyzing the teaching-learning situation. For some authors, videotaping replaces and even improves on direct observation. Sherin (2004, pp. 11-12) identified two advantages of videos over direct observation: videos provide a permanent record that can be reviewed at any time; and they can be collected and edited (Sherin, 2004, pp. 12-13) using, for example, hypermedia programs. Elaborating on these advantages, Sherin notes that video recordings enable teachers to develop new competencies as they pursue their training programs (Sherin, 2004, p. 13). For instance, they can analyze teaching sessions and relate theoretical notions to practical situations. Due to their new and easy digitizability, videos can be used to capture specific, concrete pedagogical points (Le Fevre, 2004, pp. 139, 236). Videos do this through two capabilities (Le Fevre, 2004, p. 239; Seago, 2004, p. 274):

(1) they can convey the complexity of the teaching-learning situation; and

(2) data and meaning can be extracted from a complex corpus of events so that the viewer can focus on particular educational events.

According to Abell and Cennamo (2004, p. 114), videos can also be used to compare practices longitudinally (over time in the same class) and laterally (between classes). Similarly, videos can be used comparatively to identify different teaching strategies. Moreover, when experts and novices are placed in contact through communication technologies, including videos, teaching strategies are no longer compared, but shared. Finally, some view videos as a way for future teachers to explore the teaching process and its various approaches (Fishman, 2004, p. 202). This applies equally to experienced teachers for whom videos serve as a vehicle to discover new approaches. For Seago 
(2004), the video is more than a practical extension of theoretical training; it responds to the need for a primarily practice-based training.

Stimulating reflection. Video recordings foster reflection on teaching practices in two forms:

(1) self-observation, where teachers-in-training view playbacks of their teaching lessons (usually simulated); and

(2) observation of others, where teachers-in-training view videos of other teachers.

Whether observing oneself or others, teachers-in-training are prompted to engage in a first-level reflection as they review the teaching performance. Abell and Cennamo (2004, p. 117) argue that a video recording can become "a perturbation for some students, catalyzing them to question their ideas, beliefs, and values". Le Fevre (2004, p. 248) explains that videos help future teachers discover their own beliefs about teaching. This reflection process is comparable for in-service teachers. By observing themselves and others, teachers can step back from their actions and contemplate them from a different standpoint (Le Fevre, 2004, pp. 237-238), which is the beginning of an awareness of their teaching practice. The literature acknowledges the key role of videos in encouraging future teachers to reflect. However, self-observation is not the only way to motivate teachers to reflect on their practices. In fact, observing others exposes teachers to expert practices, which can further stimulate reflection through the variety and quality of the recordings presented. For this reason, we have opted for this form of reflection in our new program.

\subsection{The importance of self-efficacy beliefs for pre-service teachers}

Self-efficacy, or the belief that one is capable of performing in a certain manner to attain certain goals (Bandura, 1989), influences an individual's choices, efforts, and persistence when confronted with obstacles or failures. In other words, if self-efficacy beliefs toward teaching strategies, methods, and innovations could be nurtured, pre-service teachers would be more inclined to put these teaching strategies, methods, and innovations into practice. Moreover, they would be more successful at using them than pre-service teachers with lower self-efficacy beliefs. For Bandura (1997), self-efficacy is both context-bound and action-specific. It also comprises two components: efficacy expectations and outcome expectations. Efficacy expectations refer to the belief in one's capacity to achieve a given action in a specific context. Many researchers refer to this concept as perceived competence. Outcome expectations refer to the belief that the action performed will result in a particular, desired outcome. Pajares and Schunk (2001), among others, refer to this second concept as perceived value.

\section{Objective}

With the aim of deepening our understanding of the potential of online videos to support the professional development of pre-service teachers, this study investigated the impact of online teaching videos on the development of self-efficacy beliefs in pre-service teachers.

\section{Online teaching videos}

199 
CWIS

28,3

\section{0}

\section{Method}

\subsection{Participants}

A sample of 400 student teachers participated in this study on the impact of online teaching videos on the development of self-efficacy beliefs in pre-service teachers. Subjects lived in the province of Ontario.

\subsection{Measures}

The questionnaire's self-efficacy scale was based on Bandura's (1977, 1989) self-efficacy theory, and employed three adapted versions of Friedman and Kass's (2002) scale (i.e. a pre- and two post-tests). Data obtained from previous investigations indicate strong Cronbach's alphas for this scale, indicating a strong positive reliability. Data obtained in this study also show strong Cronbach's alphas (ranging from 0.91 to 0.95) for the three adapted versions of the scale.

Aside from the exclusion of three statements (from a total of 19) that did not relate to our teaching situations, the scale was used unchanged. However, we adapted it slightly to the specific situations depicted in the two online videos (classroom management and the return to school), without changing the essential nature of the scale. For example, the original statement "I believe that I know how to relate my teaching to my students' interests and tastes" was replaced by "I believe that I can relate my teaching to my students' interests and tastes when I am teaching”.

\subsection{Data collection and analysis}

Participants viewed successive online videos on themes of classroom management and the return to school. Videos were extracted from the Cyberprofs.org website. Participants were asked to:

(1) fill out an initial questionnaire (pre-test) to assess their self-efficacy beliefs related to two specific teaching contexts (classroom management and the return to school);

(2) view a brief video about a specific teaching situation (classroom management);

(3) fill out a second questionnaire (post-test) to re-assess their self-efficacy beliefs related to the teaching situation presented in the first video;

(4) view a second brief video on another specific teaching situation (the return to school); and

(5) fill out a third questionnaire (post-test) to re-assess their self-efficacy beliefs related to the second teaching situation.

The questionnaires on each video ended with two open-ended questions on the impact of that video on their self-efficacy beliefs. Some of the questionnaire respondents were asked to participate in a brief telephone interview.

Figure 1 illustrates the data collection method.

Questionnaire responses were analyzed as follows. Paired sample $t$-tests were conducted on the pre-test and post-test results for both scales (classroom management and return to school) to verify the growth of self-efficacy beliefs. With missing values excluded, 135 subjects were selected for the paired sample $t$-test of the first scale 


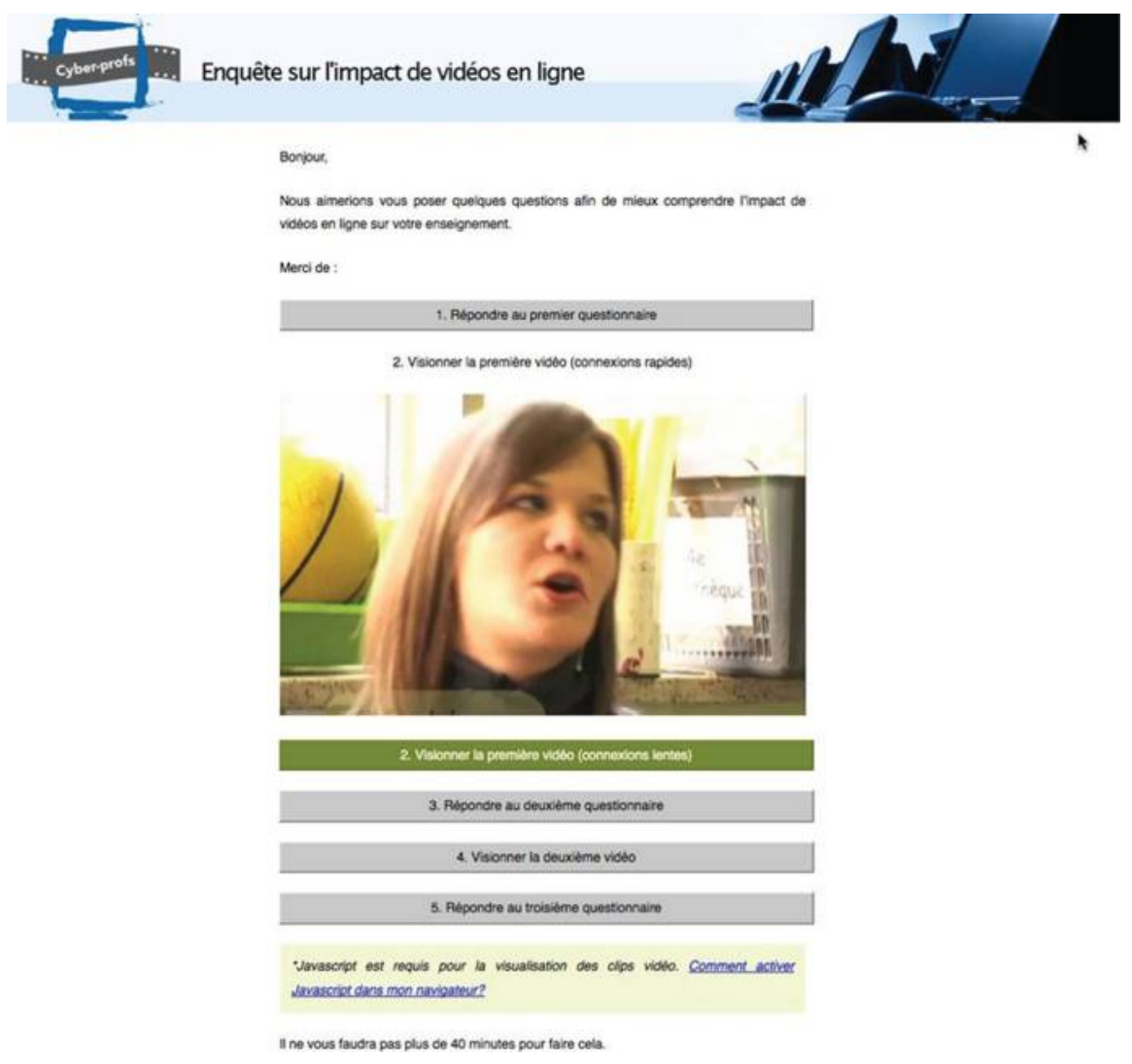

\section{Online teaching videos}

201

(classroom management) and 96 subjects were selected for the paired sample $t$-test of the second scale (return to school). The main results are presented below.

\section{Results}

The results helped us better understand the impact of online videos on current and pre-service teachers' self-efficacy beliefs with respect to two specific teaching skills or situations (classroom management and back to school). The results are highlighted in Figures 2 and 3.

Figure 2 shows higher average self-efficacy scores from pretest (74.9 percent) to post-test (79.2 percent). This difference is significant $(p<0,001)$, indicating that the online self-training tool increased feelings of self-efficacy in the respondents, particularly concening back to school issues.

Figure 3 shows the same trend as in Figure 2: a significant increase $(p<0,001)$ in average scores on the class management scale from pretest (77.2 percent) to post-test (79.2 percent). Again, the online self-training tool appears to increase feelings of self-efficacy in the respondents, particularly for class management. 


\section{CWIS}

28,3

202

Figure 2.

Paired sample $t$-test result for back to school

Figure 3.

Paired sample $t$-test result for classroom management

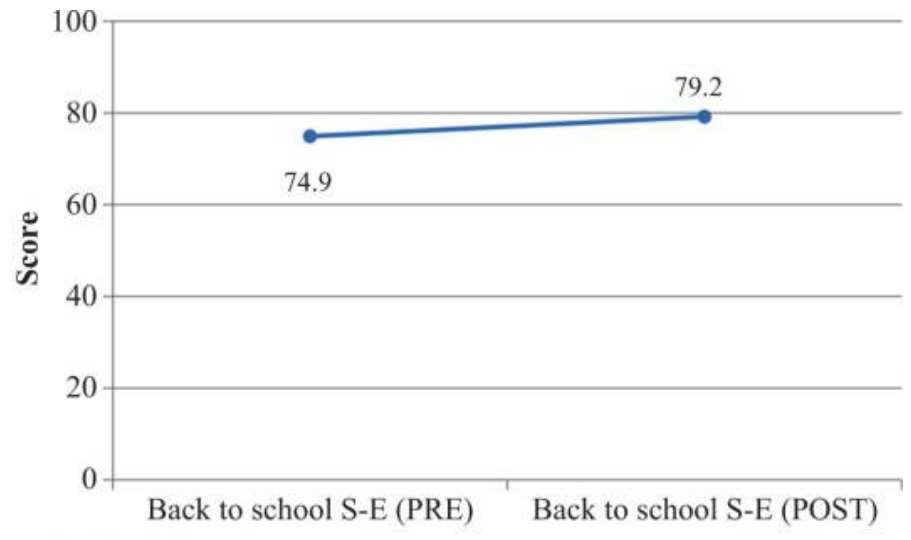

Note: ${ }^{*} p<0.001$

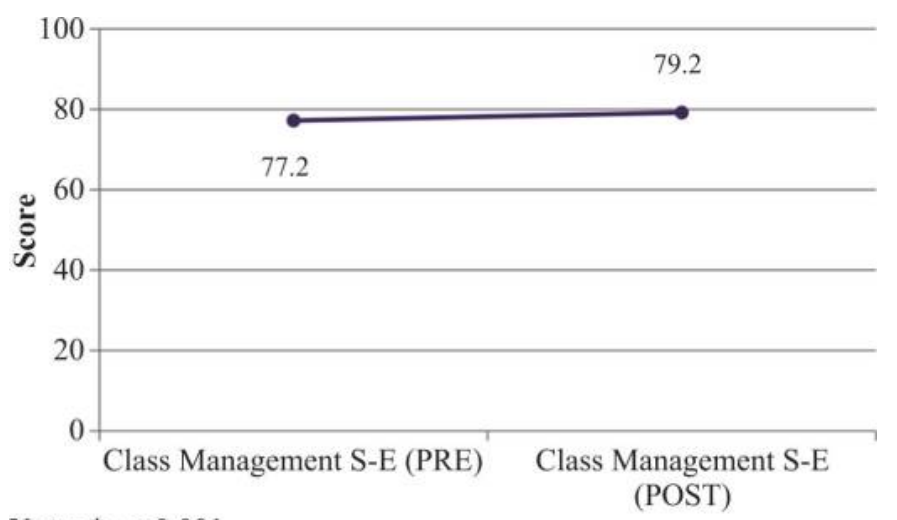

Note: ${ }^{*} p<0.001$

In both cases (Figures 2 and 3), a significant difference is seen between the pretest and post-test scores, suggesting that online self-directed training had a positive impact on the teachers' feelings of self-efficacy.

\section{Conclusion}

Taken together, these data shed light on the impact of online teaching videos on the development of self-efficacy beliefs in pre-service teachers. To recap, we examined online videos of teaching practices as a self-directed learning tool. To assess its effectiveness, we administered a questionnaire to pre-service teachers before and after watching the videos. The main finding of this development research project is that these online teaching videos appear to have contributed positively to teachers' feelings of self-efficacy. Given the importance of self-efficacy for teachers' professional development, online videos could prove highly useful to this end. Apart from the impact of the videos themselves, self-directed learning has the benefit of flexibility in terms of time and space, which is typical of open and distance learning in general. 
Furthermore, online videos can be readily adapted to individual professional development plans, according to the teacher's needs, in contrast to more formal training programs (either initial or continuing), with their relatively rigid, predetermined contents. For all these reasons, self-determined learning appears to be highly beneficial for teacher training and development, including distance learning. To advance the knowledge in this area, a more comprehensive empirical approach would be useful in future studies. For example, interviews with the participants could be videos incorporated. The qualitative results could enrich our understanding of the impact of self-determined learning models.

\section{References}

Abell, S.K. and Cennamo, K.S. (2004), "Videocases in elementary science teacher preparation", in Brophy, J. (Ed.), Using Video in Teacher Education, Vol. 10, Elsevier, Oxford, pp. 103-30.

Bandura, A. (1977), "Self-efficacy: toward a unifying theory of behavioral change", Psychological Review, Vol. 84 No. 2, pp. 191-215.

Bandura, A. (1989), Social Foundation of Thought and Action: A Social Cognitive Theory, Prentice Hall, Englewood Cliffs, NJ.

Bandura, A. (1997), Self-efficacy: The Exercise of Control, W.H. Freeman, New York, NY.

Collins, A. and Halverson, R. (2009), Rethinking Education in the Age of Technology: The Digital Revolution and the Schools, Teachers College Press, New York, NY.

Desjardins, J. (2000), “Analyse critique du champ conceptuel de la formation réflexive”, thèse de doctorat non publiée, Université de Montréal, Montréal, Canada.

Fishman, B.J. (2004), "Linking on-line video and curriculum to leverage community knowledge", in Brophy, J. (Ed.), Using Video in Teacher Education, Vol. 10, Elsevier, Oxford, pp. 201-34.

Friedman, I.A. and Kass, E. (2002), "Teacher self-efficacy: a classroom-organization conceptualization", Teaching and Teacher Education, Vol. 18 No. 6, pp. 675-86.

Garlock, G. and Soles, P. (Hosts) (1965), "McLuhan predicts 'world connectivity", Take 30 [television broadcast], Toronto: CBC Digital Archives, April 1, available at: http://archives. cbc.ca/arts_entertainment/media/topics/342-1817/ (accessed 21 December 2009).

Le Fevre, D.M. (2004), "Designing for teacher learning: video-based curriculum design", in Brophy, J. (Ed.), Using Video in Teacher Education, Vol. 10, Elsevier, Oxford, pp. 235-58.

Meyers, J.A. (1983), “A letter from the publisher”, Time, Vol. 121 No. 1, 3 January, available at: www.time.com/time/magazine/article/0,9171,953632,00.html

Oonk, W., Goffree, F. and Verloop, N. (2004), "For the enrichment of practical knowledge: good practice and useful theory for future primary teachers", in Brophy, J. (Ed.), Using Video in Teacher Education, Vol. 10, Elsevier, Oxford, pp. 131-67.

Pajares, F. and Schunk, D.H. (2001), "Self-beliefs and school success: self-efficacy, self-concept, and school achievement", in Riding, R.J. and Rayner, S.G. (Eds), Self Perception, Vol. 2, Ablex Publishing, Westport, CT, pp. 239-65.

Poppers, M. and Lipshitz, R. (1993), "Putting leadership theory to work: a conceptual framework for theory based leadership development", Leadership \& Organization Development Journal, Vol. 14 No. 7, pp. 23-7.

Reiser, R.A. (1987), "Instructional technology: a history", in Gagne, R.M. (Ed.), Instructional Technology: Foundations, Lawrence Erlbaum Associates, Hillsdale, NJ, pp. 11-48. 
CWIS

28,3

204
Richardson, V. (2001), Handbook of Research on Teaching, 4th ed., American Educational Research Association, Washington, DC.

Schön, D.A. (1983), The Reflective Practitioner: How Professionals Think in Action, Basic Books, New York, NY.

Schön, D.A. (1987), Educating the Reflective Practitioner: Toward a New Design for Teaching and Learning in the Professions, Jossey-Bass, San Francisco, CA.

Schön, D.A. (1995), "Knowing-in-action: the new scholarship requires a new epistemology", Change, Vol. 27 No. 6, pp. 26-34.

Seago, N. (2004), "Using video as an object of inquiry for mathematics teaching and learning", in Brophy, J. (Ed.), Using Video in Teacher Education, Vol. 10, Elsevier, Oxford, pp. 259-86.

Sherin, M.G. (2004), "New perspectives on the role of video in teacher education", in Brophy, J. (Ed.), Using Video in Teacher Education, Vol. 10, Elsevier, Oxford, pp. 1-27.

Van Eijck, M. (2010), "Conceptions and characterization. An explanation for the theory-practice gap in conceptual change theory", Cultural Studies of Science Education, Vol. 2 No. 2, pp. 187-99.

\section{Corresponding author}

Thierry Karsenti can be contacted at: thierry.karsenti@umontreal.ca 